\title{
Russian-German five-year-olds: What omissions in sentence repetition tell us about linguistic knowledge, memory skills and their interrelation
}

\author{
Elizabeth STADTMILLER ${ }^{1}$ (D), Katrin LINDNER $^{1}$, Assunta SÜSS ${ }^{2}$ (D), \\ and Natalia GAGARINA ${ }^{2}$ \\ ${ }^{1}$ Ludwig-Maximilians Universität München, Germany and ${ }^{2}$ Leibniz-Zentrum Allgemeine \\ Sprachwissenschaft, Berlin, Germany \\ Address for correspondence: Email: elizabeth.stadtmiller@germanistik.uni-muenchen.de
}

(Received 8 April 2019; revised 28 February 2020; accepted 2 April 2021; first published online 5 July 2021)

\begin{abstract}
In error analyses using sentence repetition data, most authors focus on word types of omissions. The current study considers serial order in omission patterns independent of functional categories. Data was collected from Russian and German sentence repetition tasks performed by 53 five-year-old bilingual children. Number and positions of word omissions were analyzed. Serial order effects were found in both languages: medial errors made up the largest percentage of errors. Then, the position of omissions was compared to visuo-verbal n-back working memory and non-verbal visual forward short-term memory scores using stepwise hierarchical linear regression models, taking into account demographic variables and receptive language. The interaction differed between languages: there was a significant negative association between omissions in the medial position in German and the final position in Russian and the visuo-verbal n-back memory score. Our study contributes to the understanding of how working memory and language are intertwined in sentence repetition.
\end{abstract}

Keywords: sentence repetition task; omission patterns; serial order effects; n-back memory; five-year-old bilinguals

\section{Introduction}

In the last five decades, sentence repetition tasks (SRTs) have been used to evaluate children's language skills (e.g., Devescovi \& Caselli, 2007; Klem, Melby-Lervåg, Hagtvet, Halaas Lyster, Gustafsson, \& Hulme, 2015; Nag, Snowling \& Miroković, 2018;). In particular, they have proven reliable in identifying monolingual and bilingual children at risk for developmental language disorder (DLD; e.g., Abed Ibrahim \& Fekete, 2019; Conti-Ramsden, Botting \& Faragher, 2001; Hamann, Chilla,

(C) The Author(s), 2021. Published by Cambridge University Press. This is an Open Access article, distributed under the terms of the Creative Commons Attribution-NonCommercial-NoDerivatives licence (http://creativecommons.org/ licenses/by-nc-nd/4.0), which permits non-commercial re-use, distribution, and reproduction in any medium, provided that no alterations are made and the original article is properly cited. The written permission of Cambridge University Press must be obtained prior to any commercial use and/or adaptation of the article. 
Gagarina \& Abed Ibrahim, 2017; Meir, Walters \& Armon-Lotem, 2016; Tuller, Hamann, Chilla, Ferré, Morin, Prevost, dos Santos, Abed Ibrahim \& Zebib, 2018).

In an SRT, children listen to isolated sentences of differing complexity and are asked to repeat them individually. To succeed at the task, studies have suggested that the participant must actively listen and reconstruct the sentence in terms of meaningful units and morpho-syntactic structures (e.g., Marinis \& Armon-Lotem, 2015). Each of these activities involves numerous cognitive processes, including storing the phonological form, parsing and storing parts of the sentence, accessing language knowledge in long-term memory, and encoding grammatical and phonological structures. Thus, SRTs reflect a complex interrelation between a participant's knowledge of relevant linguistic structures, comprehension and production mechanisms, processing strategies and various types of memory (e.g., Nag et al., 2018; Polišenská, Chiat \& Roy, 2015; Poll et al., 2013; Riches, 2012).

\section{The relationship of SRTs to linguistic knowledge and memory}

SRT performance has been linked to linguistic knowledge and various types of memory. Klem et al. (2015) argued that their SRT exclusively measures underlying linguistic competence, yet did not specify the type of underlying linguistic knowledge evidenced. Abed Ibrahim and Hamann (2017) found that syntactic complexity has a highly relevant influence on performance in an SRT, and argue that "working memory deficits alone cannot account for the poor performance of [monolingual and bilingual children with DLD]" (Abed Ibrahim \& Hamann, 2017, p. 14).

Most researchers agree that some separate (verbal) memory components are linked to linguistic knowledge. Among them are Riches (2012) and Polišenská, Chiat and Roy (2015), who provided convincing arguments for the role of long-term memory. Many studies have focused on short-term or working memory, assuming that it has a larger (e.g., Alloway \& Gathercole, 2005; Riches, 2012) or smaller (e.g., Meir et al., 2016) influence on performance. Conti-Ramsden et al. (2001) found a significant correlation between a non-word repetition task (NWRT) and an SRT, which the authors attributed to the role of limited capacity in short-term memory (ibid., p. 747). All of these studies focused on a component of verbal memory. However, some authors have argued that any causal relationship between verbal working memory and linguistic ability is circular since a test of verbal memory must, to a certain extent, also measure language (e.g., Mainela-Arnold, Misra, Miller, Poll \& Park, 2012, p. 170). Polišenská et al. (2015, p. 116) make a similar argument, coming to the conclusion that language and memory are intricately intertwined (cf. e.g., Acheson \& MacDonald, 2009).

In this paper, we will differentiate between different types of memory, following Baddeley's (2012) model. LONG-TERM MEMORY, when it comes to linguistic knowledge, may be defined as "stored [permanent] language knowledge" (Allen, Hitch \& Baddeley, 2018, p. 2582) with unlimited capacity. SHORT-TERM MEMORY is defined as "simple temporary storage of information" (Baddeley, 2012, p. 4), and is often differentiated into visual vs. verbal short-term memory (i.e., "visuo-spatial sketchpad" vs. "phonological loop"). We will define WORKING MEMORY as "a combination of storage and manipulation" (ibid, p. 4) in a multi-component limited capacity system, including short-term memory and interconnected with parts of long-term memory (ibid., p. 18). This interconnection is enabled through the episodic buffer, which among other tasks "acts as a buffer store [...] between the 
components of WM [working memory... and] can hold multidimensional representations" (ibid., p. 15) as well as through the central executive, a complex component of working memory responsible for, beyond acting as interface, focusing attention, dividing attention between modalities and controlling task switching (ibid., p. 14).

Unlike the studies presented above, we examine both verbal and non-verbal working memory. Studies on attention and binding ${ }^{1}$ in the verbal and visuo-spatial domains of working memory have shown similar recall mechanisms and analogous limited capacity systems, sometimes seen as reflecting the role of the central executive (e.g., Hitch, Allen \& Baddeley, 2020). Dual-task paradigms using both types of working memory have confirmed the interconnectedness of the auditory and visual working memory systems (e.g., Zokaei, Heider \& Husain, 2014). Crucially, serial order effects have been found consistently both in verbal and visuo-spatial working memory tasks in adult populations (visual: e.g., Brown, Niven, Logie, Rhodes \& Allen, 2017, Hitch et al., 2020; verbal: e.g., Allen et al., 2018). With regard to sentence recall, Mainela-Arnold et al. (2012) "underscore[...] the need to study the role of metacognitive component abilities in completing non-verbal span tasks, as well" (ibid., p. 174). By comparing verbal and non-verbal memory tasks, we offer a first investigation into the role of a general memory component in sentence repetition. To our knowledge, no research to date has directly related non-verbal memory to an immediate recall SRT.

\section{Analyses of SRTS}

Studies that have considered identical repetition data have used immediate recall SRTs mainly as diagnostic instruments (e.g., Grimm, Aktas \& Frevert, 2010; Hamann \& Abed Ibrahim, 2017) or as a measure of language development (e.g., Devescovi \& Caselli, 2007). Only a few authors have considered identical repetition in monolingual typically developing (TD) children. One such example is Polišenská et al. (2015), who considered the identical repetition in an SRT in English and Czech monolingual populations in a cross-linguistic study, and described "robust results across [the] two typologically different languages” (Polišenská et al., 2015, p. 114). Considering bilingual populations, Meir et al. (2016) showed that TD Russian-Hebrew bilingual children performed significantly worse than monolingual Russian-speaking peers in a Russian SRT. The same TD bilingual children obtained comparable results to Hebrew-monolinguals in a Hebrew SRT (Meir et al., 2016, p. 16). Hamann and Abed Ibrahim (2017) showed worse performance by TD bilingual children in a society-language-German setting in a German SRT than by a monolingual group, both for identical repetition (discounting only phonological errors) and a "target structure met"-criterion, allowing for lexical substitutions when syntactic structure was maintained. Abed Ibrahim and Fekete (2019) found their SRT to be a good diagnostic tool in bilinguals, though language ability played a large role in the outcomes (ibid., p. 24). In addition, many prominent results in SRT research (including claims about the tests' sensitivity and specificity) have been based upon number of errors or error analysis rather than identical repetition (e.g., Conti-Ramsden et al., 2001).

\footnotetext{
${ }^{1}$ Binding is defined by Hitch et al. (2020, p. 280) as the process "whereby the component features of a stimulus are conjoined in integrated episodic representations in working memory."
} 


\section{Errors of omission in SRTs and serial recall}

Non-identical repetition in SRTs reveals three types of errors. Participants can change the stimuli through omissions, substitutions or additions, all of which can be phonological, lexical or morpho-syntactic. Any item may potentially be omitted or substituted. Actual error manifestations, of course, are somewhat limited by the schemata and paradigms of the respective language. Past studies have focused on linguistic categories to analyze error patterns in SRTs. Meir et al. (2016) considered-besides substitutions-omissions in the forms of 1) "sentence fragments," 2) "omission of coordinators and subordinators" and 3) "omission of prepositions" (ibid., p. 442). The authors further analyzed the second and third types of omission (functional categories). Moll, Hulme, Nag and Snowling (2015) found that function words were more likely to be omitted than content words and that these were more likely to be omitted from complex rather than simple sentences. Neither Meir et al. (2016) nor Moll et al. (2015) considered the position of omissions within the sentences.

Yet the distribution of positions may well have an influence on the omissions in the sentences produced by participants. The importance of the position of items in language acquisition was suggested by Gleitman, Newport and Gleitman (1984). Their study concluded that auxiliaries in English are learned more easily when they are in initial and not in second word position. In contrast, Bloom (1990) showed that in English language development, the three children in his multiple-case study were more likely to omit the subject than the object: subjects were omitted from obligatory context in 55\% of cases, objects in $9 \%$ (ibid., p. 500). The author explains this as stemming from the subject's placement in the initial position since "the processing load at every point is proportional to the number of yet-to-be-expanded nodes that must be kept in working memory" (ibid., p. 501) ${ }^{2}$. From this we can extrapolate that the position of items has an effect on how well they can be remembered and reproduced; certain positions - in Bloom's (1990) paper, the initial position - are more prone to omissions than others, some are more stable. However, there is no definitive answer on which position is most at risk of omission, as different studies - some using tests (Allen et al., 2018; Alloway \& Gathercole, 2005), others using natural data (e.g., Bloom, 1990; Gleitman et al., 1984) - have come to different conclusions.

In cognitive psychology, serial position effects (a term first coined by Hermann Ebbinghaus in 1885; cf. Ebbinghaus, 2013) in immediate recall experiments are well-known. In these experiments the subject hears or reads a list of items and is then asked to repeat them. Subjects generally recall those items best which were either mentioned last (RECENCY EFFECT) or very early in the list (PRIMACY EFFECT), and have the most trouble with items in the middle (e.g., Cowan et al., 1998; Yoo \& Kaushanskaya, 2016). Primacy and recency effects are well-documented in the realm of visual memory (e.g., Berry, Waterman, Baddeley, Hitch \& Allen, 2018 for recency effects in children; Brown et al., 2017 for recency and primacy effects in older adults). There is a small body of literature describing primacy or recency effects in data from monolingual children with DLD, who are known for having both language and memory problems. Gillam, Cowan and Marler (1998) focused on digit

\footnotetext{
${ }^{2}$ Bloom (1990) was of course working within a very different theoretical framework, which will not be expounded upon in the current study. Rather we would like to point out that the author also argued on the basis of position within the sentence to explain why certain items are more susceptible to omission.
} 
recall, and Mainela-Arnold and Evans (2005) considered word recall in a Competing Language Processing Task (CLPT). While Gillam et al. (1998) found a greater primacy effect in children with DLD, Mainela-Arnold and Evans (2005) found no significant primacy effect in either children with DLD or TD. They did, however, find a significant recency effect in both groups, with a greater effect in the TD group.

It is obvious that there are vital distinctions between CLPTs, word list recall and SRTs. Chief among them is the component of propositional content, i.e., there is context for each word within a sentence. Underpinning the difference between word lists and sentence recall, Allen et al. (2018) compared the recall of word lists and constrained sentences in young adults. In this context, constrained sentences contain a limited set of words, but adhere to English grammar, in order to conceptually fall "between lists and sentences" (ibid., 2018, p. 2572). Both lists and sentences were matched for number of words and amount of each word type. The authors considered the serial position of each word within the list or sentence. A clear sentence effect was found, with more correct responses and fewer errors at every position. Despite this quantitative difference, the general error curves for lists and sentences were alike, with the highest proportion of words correct in the first position, and the lowest number of words correct in the penultimate word position in this case, the seventh word. In fact, in the first two positions the authors found a smaller, albeit still significant, sentence effect than in any other position. We interpret their findings as evidence of a clear primacy effect. A recency effect seems marginally present, affecting only the final lexeme in the sentence. It is important here that-as the authors themselves noted-the "use of constrained sentences exaggerates the similarities with word lists" (Allen et al., 2018, p. 2581).

To our knowledge, only one previous study has examined serial order effects in an SRT using "natural” - i.e., non-constrained - sentences. Alloway and Gathercole (2005) considered serial position effects in an SRT to compare five-year-old monolingual children with high versus low phonological short-term memory. The 20 target sentences were taken from previous studies (Potter \& Lombardi, 1990 and Bishop, 1982). Each sentence contained a different syntactic structure, and they were matched for number of words (range six to nine). Alloway and Gathercole (2005) used two analyses, considering both substitutions and omissions regarding position within the sentence.

The first analysis used a "strict serial scoring [criterion,] according to which a word was only scored as correct if it was recalled in its original position within the sentence" (Alloway \& Gathercole, 2005, p. 211). Thus, a single omission led to scoring as incorrect all positions that followed. This classification was chosen to better differentiate between groups of participants. As a methodological step, however, it is not consistent with the traditional concept of serial recall effects. That is to say, if a word is omitted in a middle position, but the following words are repeated correctly, this - in our view - does not imply an error in multiple positions. It is unsurprising, therefore, that the authors described "superior recall at early sentence positions, followed by a reduction in recall accuracy at middle and later positions" (ibid., p. 214). This finding was heavily influenced by the authors' method of error classification and counting.

In their second analysis, the authors assigned the error occurrences to three positions: initial, medial and final position. The initial position consisted of the subject or the first noun phrase (including a subject relative clause); the final position was the last noun phrase in the matrix clause (including an object relative clause), and the medial position was everything in-between. The results of this 
second analysis showed "fewer errors in the initial sentence position compared to the medial and final position" (ibid., p. 214) as well as a significant difference in the distribution of position of errors between the high and low phonological short-term memory groups. In addition, Alloway and Gathercole (2005) found a higher frequency of errors in the last position than in the middle position. In terms of primacy and recency, the authors seem to be describing a high primacy effect, and a complete lack of recency effect.

\section{SRTs and bilingualism}

Especially for bilinguals, working memory tests are relevant tools in language assessment. Since performance in language tests is influenced by extra-linguistic factors such as age of onset (AoO), length of exposure and quantity and/or quality of input in both languages, clinical diagnostics cannot be based solely on quantitative scores in language tests. As such, SRTs have been invaluable tools in the diagnosis of DLD and its disentanglement from typical bilingual language development (e.g., Abed Ibrahim \& Fekete, 2019; Armon-Lotem \& Meir, 2016; Hamann \& Abed Ibrahim, 2017; Meir, 2018), as well as in the examination of linguistic development in TD and non-TD populations (e.g., Hamann et al., 2017). Leaving clinical distinctions aside, then, investigating TD bilingual populations allows us to observe typical - i.e., unmarked - processing characteristics, such as omission patterns, in two typologically different languages within the same individuals.

One such language pair is German and Russian, which differ greatly with regards to morphosyntax, especially word order. Word order in German is stricter than in Russian, and often regulated by sentence bracketing: for example, the finite auxiliary + past participle verb phrase is split and forms a bracket with an opening and a closing element (e.g., (1a)).

(1a) German Sentence with Sentence Bracketing

$\begin{array}{llll}\text { Das } & \text { Kind } & \text { ha-t } & \text { den } \\ \text { ART.DEF.SG.NOM.N } & \text { child } & \text { AUX-3SG } & \text { ART.DEF.SG.ACC.M }\end{array}$

opening element

Vater ge-ruf-en

father PST.PTCP-call- PST.PTCP

closing element

'The child (has) called the father.'

(1b) Russian Translation

$\begin{array}{lll}\begin{array}{l}\text { Rebënok } \\ \text { child.NOM }\end{array} & \text { pozva-1 } & \text { otc-a. } \\ \text { call.PFV-PST.SG.M } & \text { father-ACC }\end{array}$

'The child (has) called the father.'

Note: Russian makes no distinction with regard to marking definite articles. Thus, the Russian sentence might in specific contexts also read "A child (has) called a father." In the further Russian examples this ambiguity has been marked using brackets.

With sentence bracketing, a German sentence is divided into parts: the first is delimited on the right side by the finite verb of the matrix clause. The second is between the opening and closing elements - e.g., (1a). With regard to information structure in unmarked order, known information (frequently the subject of a given 
phrase) precedes new information. German also allows for topicalization (of objects or adverbials), in which the topic is moved left out of the brackets and put in front of the finite verb (into topic position).

In Russian, word order is more flexible, and governed by information structure: the unmarked word order Subject-Verb-Object reflects this, with the new information at the end (e.g., King, 1995; Švedova, 1982). However, these features can be best observed in texts or conversational data, and cannot be directly considered in isolated sentences, such as found in an SRT. Comparing the two languages, Russian has fewer function words ${ }^{3}$, such as determiners or auxiliary verbs (e.g., (1b)), than German. This information is provided by inflection, context or word order. Thus, Russian sentences often contain fewer words than German.

\section{The current study}

There is a research gap concerning the relationship of recall of items and their position within a sentence in both monolingual and bilingual populations. Also, there have been no studies comparing frequency or position of omissions to memory skills, to our knowledge. Nor has the distribution of omission errors in children's performance in SRTs been investigated in detail.

Our study scrutinized the performance of bilingual children in two language-specific SRTs from typologically different languages, German and Russian. We examined the relationship of omissions in SRTs with children's receptive language skills and performance in two memory tests. The study came about within a larger research project, examining the German and Russian SRT for use in a clinical setting (Lindner, Held, Lomako \& Gagarina, 2014).

As described above, three types of errors may occur in an SRT: omissions, substitutions and additions. Omissions, in our view, represent a more uniform cognitive process, "leaving out A," while the process underlying substitutions is "replacing A with B," where B is highly variable and susceptible to many different influencing factors (cf. Meringer \& Mayer, 1895 on slips of the tongue; Nag et al., 2018). Thus, the cognitive process of omission has one fewer variable to be accounted for than substitution. It should be noted that this formulation is a simplification, and that we do not assume that a substitution can be broken down into "omission + addition." Neither do we believe that the process of omission is a simple one; on the contrary, errors of omission are highly complex phenomena, which involve, among others, categorial features and serial order effects. We will concentrate on omissions in the initial, medial and final position of the sentence, as defined below.

Given the limited processing capacity of working memory, there are many factors which influence children's processing, including entrenchment, prosodic salience and, crucially, position within an utterance. What role does serial position-i.e., "vulnerable" or "robust" positions within the sentence-play in sentence repetition, and are there differences between German and Russian? Can a participant's updating skills, subsumed under visuo-verbal or non-verbal working memory, predict the likelihood that these "vulnerable" slots will be filled? The specific research questions are formulated as follows:

\footnotetext{
${ }^{3}$ Though our analysis does not consider functional categories, it is of note that when children omit words in SRTs, these are most often function words. This is due, among other things, to low saliency of these mainly unmarked items (e.g., Meir et al., 2016; Moll et al., 2015).
} 


\section{Research questions}

1. How many words do children omit in an SRT, and in what positions? Are there serial position effects, i.e., primacy and recency effects?

a. in the German SRT

b. in the Russian SRT

Based upon the small existing body of literature, we predict (i) robust primacy effects, with the smallest number of omissions in both languages in the initial position (Alloway \& Gathercole, 2005; Allen et al., 2018; Gillam et al., 1998). This would be strong evidence for the role of language-independent processing costs.

We also predict (ii) recency effects, i.e., fewer errors will be found in the final position than in the medial position in both languages given sentence-lengthindependent analysis (e.g., Allen et al., 2018; Mainela-Arnold \& Evans, 2005).

2. Is there an association between the position of omissions in the German SRT and visuo-verbal n-back working memory or visual forward memory, when receptive language is taken into account?

3. Is there an association between the position of omissions in the Russian SRT and visuo-verbal n-back working memory or visual forward memory, when receptive language is taken into account?

Of course, other linguistic components play a role in sentence processing and sentence repetition. By controlling for receptive language skills, we hope to subdue the influence of linguistic knowledge to a certain extent, without facing insurmountable floor effects that might be found in tests of morphosyntax or production in a bilingual population with diverse AoOs (cf. Abed Ibrahim \& Fekete, 2019). We predict (iii) that memory skills, both visuo-verbal and non-verbal, will be negatively associated with errors in the medial position, which would strengthen any finding of primacy or recency effects in both languages (cf., Hitch et al., 2020; Mainela-Arnold \& Evans, 2005; Zokaei et al., 2014). We predict (iv) no significant differences between Russian and German, but rather predict the role of memory will remain the same across languages, when linguistic knowledge is taken into account. This would corroborate high involvement of non-verbal and/or non-linguistic memory skills in sentence repetition. An association of non-verbal visual memory would provide strong evidence for language-independent and domain-general processing mechanisms and memory.

\section{Method}

\section{Participants}

Our study analyzed data from 53 (27 girls, 26 boys) Russian-German TD bilingual children (Table 1), in their final year of kindergarten, i.e., before they had received systematic meta-linguistic education. The children were recruited from various kindergartens in Berlin, Munich and Lower Bavaria. On the basis of a parental questionnaire (adapted from Gagarina, Klassert \& Topaj, 2010) and IQ tests (Roid, Miller, Pomplun \& Koch, 2013), children with deficits in hearing, or with atypical neurological or cognitive development were excluded. Children whose performance was lower than one standard deviation (SD) below the average in an NWRT in either language (Lindner, Held, Lomako \& Gagarina, 2014; German version: Wagner, 
Table 1. Descriptive Statistics for the Current Sample

\begin{tabular}{lll}
\hline Variable & mean (SD) & range \\
\hline Age & $5 ; 3(0 ; 2)$ & $5 ; 0-5 ; 7$ \\
\hline AoO German & $1 ; 7(1 ; 4)$ & $0 ; 0-4 ; 0$ \\
\hline length of exposure & $44.02(15.69)$ months & $18-65$ months \\
\hline IQ & $100.09(7.67)$ & $85-120$ \\
\hline German NWRT (sum of errors) & $21.79(14.02)$ errors & $3-73$ errors \\
\hline Russian NWRT (sum of errors) & $22.17(12.13)$ errors & $2-47$ errors \\
\hline $\begin{array}{l}\text { German receptive language } \\
\text { composite score }\end{array}$ & $\begin{array}{l}67.09 \%(13.66 \%) \\
\text { items correct }\end{array}$ & $\begin{array}{l}31.15 \%-93.44 \% \\
\text { items correct }\end{array}$ \\
\hline $\begin{array}{l}\text { Russian receptive language } \\
\text { composite score }\end{array}$ & $\begin{array}{l}80.32 \%(11.69 \%) \\
\text { items correct }\end{array}$ & $\begin{array}{l}35.71 \%-95.24 \% \\
\text { items correct }\end{array}$ \\
\hline
\end{tabular}

Held \& Lindner, 2013; Russian version: Gagarina \& Valentik-Klein, 2013) were also excluded, since this task is considered reliably differential for DLD (e.g., Thordardottir \& Brandeker, 2013). The children had at least one Russian-speaking parent (when only one, always the mother). The children's receptive language skills were measured in both languages. All children were within one SD from the group mean in receptive language, another robust exclusion criterion for DLD (cf. e.g., Bishop, 2004), in at least one of their languages. Before beginning the study, all procedures were approved by the German Linguistics Society ethics committee (Ethikkommission der Deutschen Gesellschaft für Sprachwissenschaft, DGfS). Parents provided written, informed consent before participation in the study.

A paired-samples two-tailed t-test to compare the receptive language composite score in German and Russian found a significant difference: $\mathrm{t}(52)=-5.56, \mathrm{p}<.001$. This means that children's Russian receptive language skills are significantly better than their German receptive language skills. We may presume that, on average, Russian is the children's dominant language.

\section{Procedure and materials}

Each participant was tested individually in a quiet room in their kindergarten. The tests for this study were embedded in a larger test battery. Each child had two sessions per language as well as a separate session for IQ and cognitive tests. The test order was customized individually to maximize motivation, allowing for flexibility if the child expressed disinterest or preferred a different order. The German SRT was always the final test of the second and last session, since, in pilot studies, children showed such high motivation in performing it that it could be used as a reward. The tests for each language were at least one week apart. Audio was recorded using the Zoom H4next audio recorder.

\section{German receptive language tests}

The children's German receptive language was measured using a composite score of receptive vocabulary and sentence comprehension raw scores. Since norms exist only for monolingual German children, these were not considered. Receptive vocabulary 
was measured using subtests from the Patholinguistische Diagnostik bei Sprachentwicklungsstörungen (PDSS; Kauschke \& Siegmüller, 2009), in which children are orally presented 20 verbs and 20 nouns and must point to the correct image. Each image is presented with a semantically near and a semantically far distractor. There is no stop rule. Sentence comprehension was measured with TROG-D: Test zur Überprüfung des Grammatikverständnisses (Fox, 2011), in which the child is orally presented 21 blocks of four sentences and must choose the correct picture out of four possibilities for each sentence. Each item includes three distractors, either lexical or morpho-syntactic in nature. A block is scored as incorrect if one or more sentences are identified incorrectly and the test ends if a child has five consecutive incorrect blocks.

The composite score was the sum of all raw scores, leading to a maximum total score for German receptive language of 61 .

\section{Russian receptive language tests}

Russian receptive language was determined using subtests from the Russian Language Proficiency Tests for Multilingual Children (SRUK, Gagarina et al., 2010; Gagarina, Klassert \& Topaj, 2015), which provides bilingual norms. In order to maintain comparability with the German scores, however, we used the same system of composite score of individual raw scores. In the receptive vocabulary subtest, the children heard ten nouns and ten verbs and pointed to the correct image out of four (including a phonological, a semantic and an unrelated distractor). The subtest for sentence comprehension included eleven test sentences, presented orally. Again, the child chose from four images, with lexical (i.e., substituting subject, object, predicate or some combination of these) or morpho-syntactic (e.g., changing perfectivity) distractors. Neither subtest has a stop rule.

The maximum total score for Russian receptive language was 31 .

\section{Memory tasks}

Children were tested with two memory tasks. The first was the subtest Forward Memory from the non-verbal IQ test Leiter International Performance Scale (Leiter-3; Roid et al., 2013). This subtest is a short-term memory task, in which the participant is presented with visual cues in the form of child-friendly pictures of frequent items. The examiner points to the pictures in a certain order and the participant must point to the same items in the same order. For five-year-olds, the task starts with two pictures. The maximum number of pictures is eight. If a child repeats seven cumulative sequences incorrectly, the task is stopped. Task and instructions are performed entirely non-verbally in an attempt to minimize the component of verbal memory. It is likely that participants use internal verbal rehearsal to memorize the order they must show, but the extent to which this is the case cannot be measured. This task reflects visual short-term memory abilities, since the information given must be stored but not necessarily manipulated.

The second task used was a test for n-back memory, developed within the research project (Held, Lindner \& Gagarina, 2013). The test was performed with verbal instructions, given in Russian or German depending on a child's language dominance as determined with linguistic tasks. In the n-back memory task, pictures are presented to the child in a booklet. Each page contains an animal (dog, cat or cow) or a toy vehicle (fire truck, ambulance or car). The child first decides upon a noise for each item (typically moo for cow, brrum for car, etc.) and is asked to 
produce this noise every time the item appears. Certain pages contain a picture of a parrot. Whenever the parrot appears, the child must repeat the noise of the last animal they saw. The distance between test item and parrot is between one and three distractors (vehicles). Participants practice the representative noises for the animals and toys and participate in four practice trials with the parrot before the task starts. The child is presented with two warm-up items; if they master these, the test is administered. If not, three further examples are presented before the test items are presented. There are nine test items (i.e., animals). There is no stop rule. Since the child is presented with visual stimuli, but additionally performs a verbal (but non-linguistic) task, we regard this test as measuring VISUO-VERBAL working memory. The working memory component lies in the processing part of the task: the child must not only memorize, but process the stimulus visually and assign a verbal sound to each animal or toy at the same time.

\section{Sentence repetition tasks}

The children were given two language-specific SRTs, one in German and one in Russian (Table 2). In both tests, the sentences were recorded by a native speaker and presented in a PowerPoint presentation featuring a bear going on a treasure hunt (pictures for the German SRT modified from Marinis, Chiat, Armon-Lotem, Piper \& Roy, 2011 with the authors' permission). Each sentence is presented once, with exceptions made only for external interruptions. At the end of the test, the bear reaches a treasure chest and the participant is rewarded with a sticker.

The German SRT (Lindner, Schmitt \& Kühfuss, 2013), was developed within the research project, with the goal of better determining risk for DLD in a RussianGerman population. Reviewing a number of existing German SRTs, we found them unsuitable: they examine a smaller set of structures (e.g., Grimm et al., 2010), or present more sentences, often aimed at older children (e.g., Hamann, 2013). Our German SRT presents sentences with a complexity suitable to kindergarten children from four years onwards. The vocabulary and collocations were chosen from typical kindergarten language use (Augst, 1985), compared with standard vocabulary tests (Bockmann \& Kiese-Himmel, 2012; Grimm \& Doil, 2006) and German language tests for preschool children (Grimm et al., 2010; Wettstein, 1987). It includes day-to-day activities and semantic fields such as shopping and playing, as well as categories like familiar (fairytale) figures, animals, toys and vehicles. The most relevant syntactic structures of German are presented in two to four sentences: for example, the finite verb in second vs. last position, sentence bracketing, embedded clauses, negation and wh-questions (see Appendix, Table A1, for full list of German sentences).

The Russian SRT was based on the long version of Russian LITMUS-SRep (LITMUS Sentence Repetition Tasks, Marinis \& Armon-Lotem, 2015, developed within the COST Action IS0804, http://www.bi-sli.org/index.htm, cf. Meir, Walters \& Armon-Lotem, 2016). The test, originally with 56 sentences, was reduced to 30 and piloted with monolingual Russian-speaking children. Since this test was intended for younger children than those in Marinis and Armon-Lotem's (2015) population, simple sentences and sentences with three words were added. As such, the Russian SRT tested ten different structures: various word order simple sentences (SVO, SOV, OVS), sentences with coordination and subordination, negation, subject and object relative clauses, conditionals and object and oblique questions (see Appendix, Table A2 for full list of Russian sentences). The Russian SRT contains fewer words 
Table 2. Language-Specific Sentence Repetition Tasks

\begin{tabular}{lll}
\hline \multicolumn{1}{c}{ German } & \multicolumn{1}{c}{ Russian } \\
\hline test & \multicolumn{1}{c}{ project development } & $\begin{array}{l}\text { reduced and adapted version of } \\
\text { Marinis \& Armon-Lotem (2015) and } \\
\text { Meir \& Armon-Lotem (2015) }\end{array}$ \\
\hline number of sentences & 30 meaningful sentences + 2 warm-up sentences \\
\hline length of sentences & $3-12$ words & $3-7$ words \\
\hline sum of tokens in test & 200 & 153 \\
\hline complexity & 3 levels, sorted by typical order of acquisition \\
\hline sequence & sentences randomized within each level \\
\hline PowerPoint images & $\begin{array}{l}\text { Marinis, Chiat, } \\
\text { Armon-Lotem, Piper \& }\end{array}$ & $\begin{array}{l}\text { COST Action (Marinis \& Armon-Lotem, } \\
\text { Roy (2011) }\end{array}$ \\
\hline
\end{tabular}

than the German (153 vs. 200 in total), since German uses fewer morphological markings to express grammatical and information structure and more function words. Russian, on the other hand, has richer inflectional morphology with fewer function words than German.

\section{Coding and scoring}

Recordings were transcribed orthographically according to German and Russian spelling, using the program CLAN - Computerized Language Analysis (MacWhinney, 2000). First, the sentences were coded for identical repetition. In our study, this term is taken literally and means the repetition of the stimulus sentence with zero deviations. As for position effects, in German, the assignment of the initial, medial and final positions suggests itself through sentence bracketing. However, using this German-specific syntactic structure would prohibit direct comparison with Russian, as Russian sentence structure varies greatly.

Therefore, we applied a stricter, but at the same time very broad, criterion, so that three positions can exist in each sentence. These positions are defined post-hoc, using the specific utterances found, i.e., they do not reflect any words or phrases within each sentence. Rather, they refer to the placement of the omission relative to words which were repeated. Therefore, each position can be different for each sentence and each child. The positions themselves are defined as: INITIAL (there are no items before the deleted item, e.g., (2) for German, (3) for Russian), FINAL (there are no items after the deleted item, e.g., (4) for German, (5) for Russian) and MEDIAL (there are items both before and after the deleted item, e.g., (6a) and (6b) for German, (7) for Russian). Any of these positions can contain one or more words (e.g., (4) and (6b) for German, (5) for Russian), up to the amount of words in the sentence minus one for initial and final deletions (there must be at least one word after or before the omission, respectively) and minus two for medial omissions (there must be at least one word before and one word after the omission). Defined thus, the initial position will not be highly affected by sentence length. The final position will also be relatively independent of length, since it allows for reductions of many items (e.g., (4), where there are six final omissions). Additionally, this allows for a 
more, though not totally, word-type independent analysis. Of course, certain word types are only found in certain sentence slots, when these are defined on a word-by-word basis. This is due, on one hand, to the test material, which was limited in the number of sentences presented (thus, e.g., prepositions are never found as the first word in a sentence). On the other hand, it is simply the nature of the syntax of the languages in question (e.g., prepositions and determiners are never the last word in a sentence). By broadening the definition of the three positions beyond a single word or phrase slot, any word can be scored in any position, if the surrounding lexemes are also omitted (or not). For example, in (4) the conjunction wenn 'if/when' or in (5), the preposition $v$ 'in/near' is counted as an omission in the final position, because there is no material after it. Thus, since the positions are determined post-hoc, there are more opportunities to omit a word from any functional category in any position. We will refer to omissions only of complete words. Omissions in our sense include, but are not limited to, utterances other researchers have considered "fragments" (e.g., Meir et al., 2016), as long as each "fragment" is at least one complete word. Word order errors in which the number and type of lexemes are unchanged, as well as omissions of phonemes or morphemes within words were considered morpho-syntactic substitutions, and as such were not taken into account for this study. Additions of words (e.g., utock $i$ in (7)) were not further considered for this study, either.

(2) One initial omission in German

\section{Stimulus:}

\begin{tabular}{|c|c|c|c|}
\hline $\begin{array}{l}\text { Dass } \\
\text { That }\end{array}$ & $\begin{array}{l}\text { die } \\
\text { ART.DEF.SG.NOM.F }\end{array}$ & $\begin{array}{ll}\text { Sonne } & \text { schein-t, } \\
\text { sun } & \text { shine-3SG }\end{array}$ & $\begin{array}{l}\text { freu-t } \\
\text { please-3SG }\end{array}$ \\
\hline den & Zauberer. & & \\
\hline ART.D & EF.SG.ACC.M Magician & & \\
\hline
\end{tabular}

\section{Child:}

$\begin{array}{lllll}\text { der } & \text { Sonne } & \text { schein-0 } & \text { freu-t } & \text { den } \\ 0 \quad \text { ART.DEF.SG.NOM.M } & \text { sun } & \text { shine-0 } & \text { please-3SG } & \text { ART.DEF.SG.ACC.M } \\ \text { Zauberer. } & & & & \\ \text { magician } & & & & \end{array}$

(3) One initial omission in Russian

\section{Stimulus:}

$\begin{array}{lllll}\text { Vrač-a } & \text { vide-la } & \text { sestr-a } & \text { u } & \text { bol'nic-y. } \\ \text { doctor-ACC } & \text { see.IPFV.PST-SG.F } & \text { nurse-NOM } & \text { near } & \text { hospital-GEN }\end{array}$
'(The/a) nurse saw (the/a) doctor near the hospital.'

\section{Child:}

$\begin{array}{lllll}0 & \text { sestra } & \text { vide-la } & \mathrm{u} & \text { bol'nic-y. } \\ & \text { nurse-NOM } & \text { see.IPFV-PST.SG.F } & \text { near } & \text { hospital-GEN }\end{array}$

(4) Six final omissions in German

\section{Stimulus:}

$\begin{array}{ll}\text { Die Kind-er } & \text { spiel-en draußen, wenn } \\ \text { ART.DEF.PL.NOM child-PL } & \text { play-3PL outside COND } \\ \text { die } \quad \text { Sonne } & \text { schein-t. } \\ \text { ART.DEF.SG.NOM.F sun } & \text { shine-3SG } \\ \text { 'The children play outside when the sun shines.' }\end{array}$


Though the coding scheme described above minimizes the effects of length and complexity, more errors of omission are of course found in longer sentences in both languages (see Appendix, Tables A3 and A4).

\section{Results}

In this study we investigated omissions in a German and a Russian SRT in relation to memory skills, controlling for linguistic knowledge in the respective language and demographic variables AoO (for German), age, IQ and sex. AoO and length of exposure could not be considered in the same model, since they are, of course, highly correlated. Replacing the former with the latter revealed no difference and is therefore not reported on. Data analysis was performed using Microsoft Excel (2010) and $\mathrm{R}$ environment ( $\mathrm{R}$ Core Team, 2018). Two scores were missing from the n-back memory test. These were imputed using predictive mean matching of all tests (r MICE-package; von Buuren \& Groothuis-Oudshoorn, 2011). Since the overarching project is a longitudinal study, we were able to compare the imputed data to the measuring points before (both participants) and after this study (one of the two). The imputed data was no more than one point different than the score in the earlier or later measuring point.

\section{Research question $1 a$}

The first research question asked after number and positions of omissions in the German SRT. The test contained 200 words, so that the sample of $n=53$ contained a total of 10600 tokens to be repeated. Of these, $830(8 \%)$ were omitted. In Figure 1 the range of possibilities between zero and 43 omissions is covered; there are no clusters. We see three participants with an amount of omissions more than two SDs above the group average.

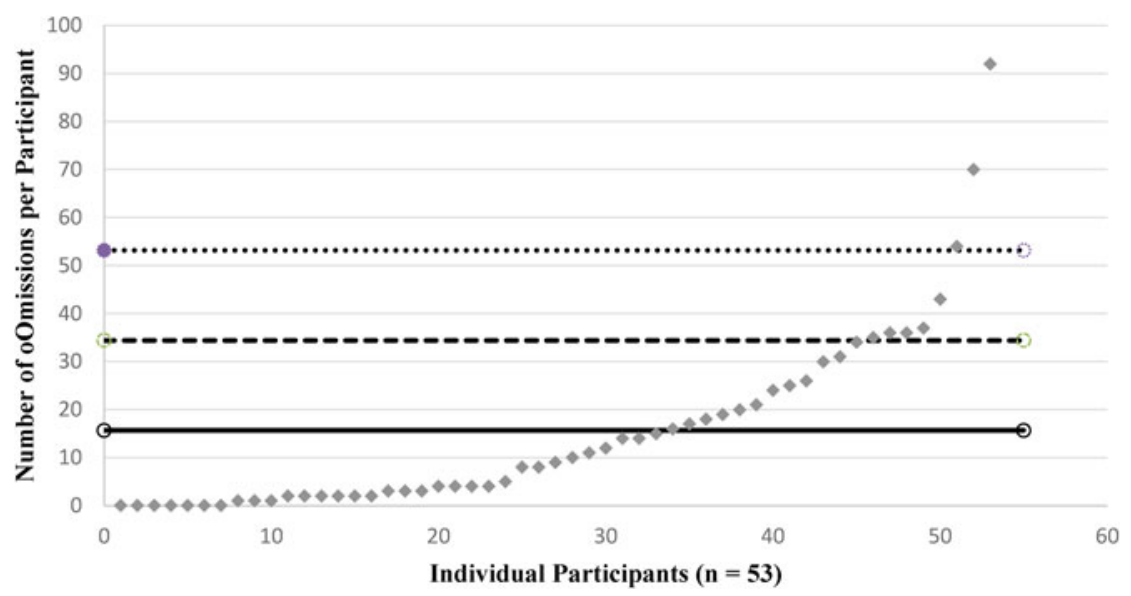

Figure 1. Omissions per participant in the German SRT, raw scores, sorted from least to most (solid line $=M$, dotted lines $=1 S D / 2$ SDs above $M$ ) 
Table 3. Omissions by Position in the German SRT

\begin{tabular}{llll}
\hline $\begin{array}{l}\text { omissions for } \\
n=53\end{array}$ & initial position & medial position & final position \\
\hline 830 & $191(23 \%)$ & $560(67 \%)$ & $79(10 \%)$ \\
\hline
\end{tabular}

Note: Percent omitted refers to the percentage out of total omissions (830)

In order to verify that omissions are representative of children's skill in the German SRT, a Pearson correlation was performed. It should be recalled that identical repetition here is a very strict criterion, allowing for no divergence from the stimulus, and it is entirely possible for a child to receive an identical repetition score of zero due to phonological and/or morpho-syntactic substitutions, while making no omissions. The identical repetition score $(M=10.00, S D=7.31)$ and the number of omissions $(M=15.68, S D=18.91)$ were significantly negatively correlated, $r(51)=-.72, p<.001$. This was proofed using a hierarchical linear regression model. When demographic variables, receptive language skills and short-term forward and n-back working memory were taken into account, a model to predict identical repetition including number of omissions was more significantly predictive than one without, $\Delta F=10.21$, $p<.01, \Delta R^{2}=.08$. Number of omissions was negatively associated $(b=-.16, t(44)$ $=-3.2, p<.01)$ with identical repetition, and mitigated the effects of AoO and German receptive language. Given the classification above, medial deletions are by far the most common type of omission in the German SRT, followed by initial and then final omissions (Table 3).

In fact, of the 47 children whose German SRT showed any omissions (Figure 1), only one had no medial omissions. This participant showed one omission (initial omission of an article) and had an above average number of identically repeated sentences. 19 of 47 participants had no initial deletions and another 19 of 47 had no final deletions. Twelve children of these two groups overlap, in that they had neither initial nor final deletions, leaving 14 children who had either no initial deletions OR no final deletions. If children omitted items only from the medial position, they tended to perform better overall than the children who omitted items in the initial or final positions. When the categorical variable "only medial omissions" was added to the hierarchical model above, it became significantly better at predicting number of identically repeated sentences, $\Delta F=6.93, p<.01, \Delta R^{2}=.05$. The categorical variable "only medial omissions" was the best individual predictor, $b=4.11, t(43)=2.63$, $p<.05$ after German receptive language $(b=.28)$ and age of onset $(b=-.12)$. This is evidence of both primacy and recency effects in the German SRT, confirming predictions (i) and (ii) for German.

\section{Research question $1 b$}

Number and positions of omissions in the Russian SRT contrast with the German. The test contained 153 words, so that the sample using $n=53$ contained a total of 8109 tokens to be repeated. Of these, 269 (3\%) were omitted. Twenty participants show zero omissions (compared to seven participants in German; Figure 2). Four children were more than two $S D$ s above the group mean.

The number of omissions $(M=5.11, S D=7.58)$ again showed a significant negative correlation with the identical repetition score $(M=16.13, S D=7.49), r(51)=-.77$, 


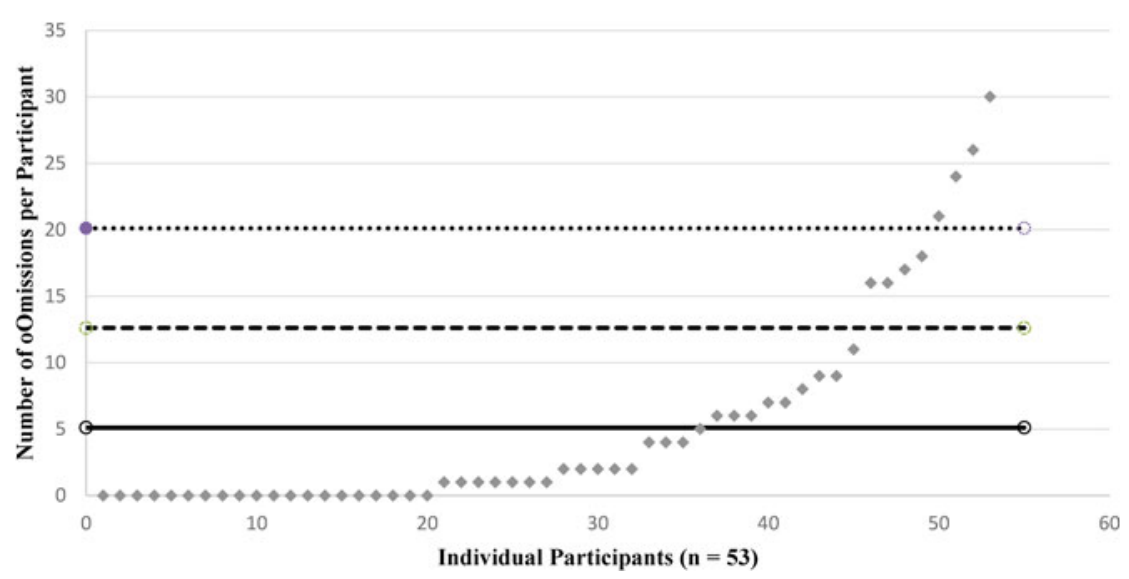

Figure 2. Omissions per participant in the Russian SRT, raw scores, sorted from least to most (solid line $=M$, dotted lines $=1 S D / 2 S D$ s above $M$ )

$p<.001$. Analogous to the German, this correlation was checked with a hierarchical linear regression model, taking into account demographic variables, receptive language skills and short-term and working memory skills. Again, the addition of number of omissions significantly improved the model, $\Delta F=25.16, p<.001, \Delta R^{2}$ $=.20$. The number of omissions was a significant individual predictor, outshining all other predictors, $b=-.66, t(43)=-5.02, p<.001$. Omissions may thus be considered a robust indicator of performance in both the German and Russian SRT.

As Figures 1 and 2 show, the children make significantly fewer omissions in the Russian SRT as compared to the German. This is illustrated more clearly in Figure 3, and confirmed using a paired two-tailed t-test; $\mathrm{t}(52)=3.64, \mathrm{p}<.001$. As a result, there are also fewer omissions in each position in Russian than in German. This effect is negated by the use of percentages (Table $3 \&$ Table 4 ).

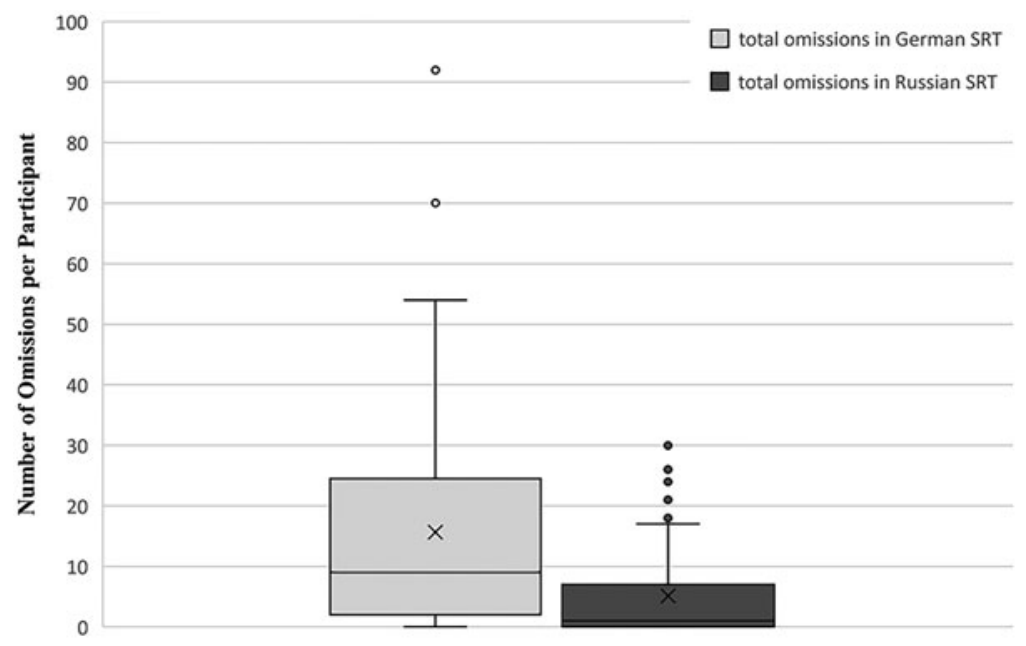

Figure 3. Boxplots comparing omissions per participant in the German and Russian SRTs 
Table 4. Omissions by Position in the Russian SRT

\begin{tabular}{llll}
\hline $\begin{array}{l}\text { omissions for } \\
\mathrm{n}=53\end{array}$ & initial position & medial position & final position \\
\hline 269 & $42(16 \%)$ & $124(46 \%)$ & $103(38 \%)$ \\
\hline
\end{tabular}

Note: Percent omitted refers to the percentage out of total omissions (269)

Although medial omissions are, as in the German SRT, the most common, they are followed by final and then by initial deletions in the Russian SRT (Table 4).

As compared to 47 (out of 53) children in the German SRT who omitted at least one word, in the Russian SRT 33 children's SRTs contained omissions. Of these 33, four children showed no medial omissions. This small number reveals a qualitative divergence. Two of the four match the German finding: they have one or two omissions in total, in the final position, and an above average performance in identical repetition. The other two participants with no medial omissions have a high number of final omissions ( 5 and $23, M=3.12, S D=5.58$ ), and perform below average on identical repetition (respectively 16 and $5, M=16.13, S D=7.49$ ). Similar to German, 21 of 33 participants with omissions had no initial and another 15 of 33 had no final omissions. Twelve children of these groups overlap. Interestingly, of these 12 children, only one is also a part of the group of-coincidentally-12 children with only medial omissions in German described above.

Unlike in German, the categorical variable "only medial omissions" did not improve the hierarchical model, $\Delta F=.80, p<.5, \Delta R^{2}=.01$. The categorical variable "only medial omissions" was insignificant as a predictor, $b=-1.50, t(44)=-.90, p<.5$ and did not mitigate number of omissions. Rather, number of omissions remained the best (and only significant) individual predictor (see above).

Unfortunately, this analysis could not be performed using the categorical variable "only final omissions," as only two participants fall into this category. Both have an above average number of identical repetitions (18 and 20) and a below average number of omissions (respectively 2 and 1). These findings indicate a robust primacy effect, but an insignificant recency effect, confirming prediction (i) for Russian, but rebuking prediction (ii).

\section{Research question 2}

The second research question asked what association exists between memory skills (i.e., non-verbal short-term and visuo-verbal working memory) and omissions in each position. We conducted three stepwise linear hierarchical regressions. Identical repetition could not be taken into account in the same model as number of initial, medial or final omissions due to additivity, $r(51)>.7$. Mahalanobis distance scores, Cook's distances and leverage cut-offs (for descriptions of these tests cf., Tabachnick \& Fidell, 2007, pp. 62-67) were calculated for each regression. If a child was above the cut-off in two or more tests, they were considered an outlier and removed from the model. Linearity, normality, multicollinearity, homogeneity and homoscedasticity were met for all data sets after removing outliers.

The first model considered number of omissions in the initial position as the dependent variable and demographic variables (age, AoO, IQ, sex), German receptive 


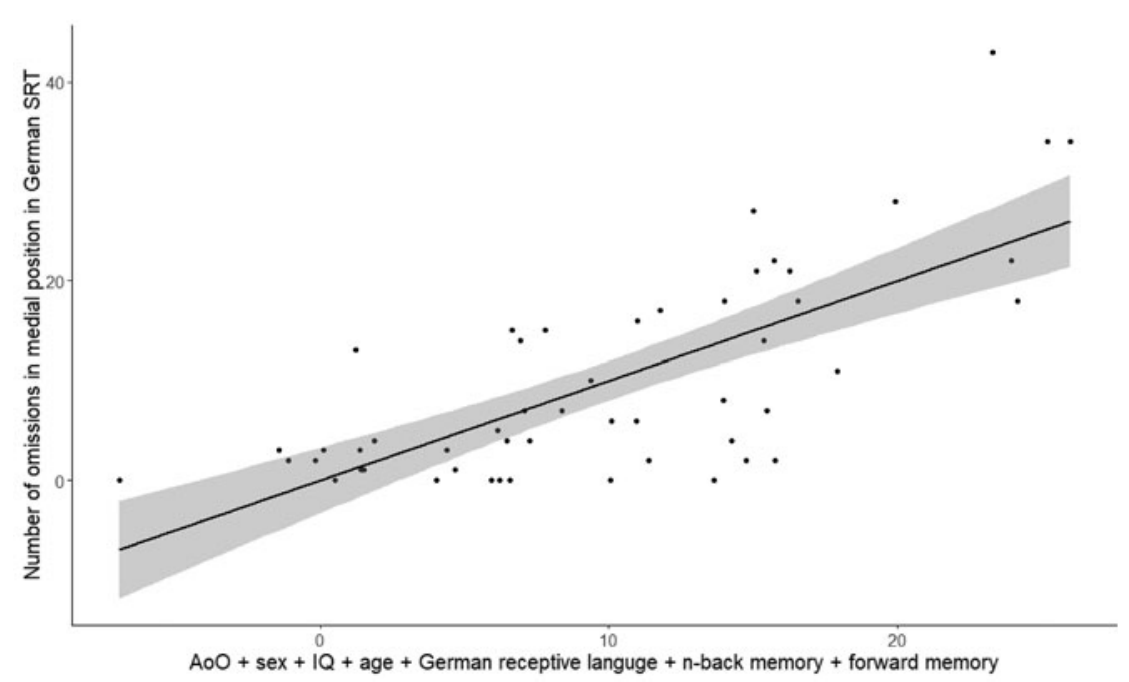

Figure 4. Scatterplot of regression of AoO, sex, IQ, age, German receptive language, visuo-verbal n-back memory and visual forward memory with number of omissions in the medial position in the German SRT

language skills and the two memory scores as independent variables. Two outliers were removed (thus, $\mathrm{n}=51$ ). Step one included demographic variables. The model was not significant and explained only a small amount of variance, $F(4,46)=1.91, p<.5, R^{2}$ $=.14$. No individual variable was significantly associated with number of initial omissions, though AoO came closest, $b=.10, p<.1$. The next model, which added German receptive language, was not significantly improved, $\Delta F(1,45)=2.06, p<.5$, $\Delta R^{2}=.04$, but the small effect of AoO disappeared. The third step included visuo-verbal n-back memory. Once again, the model was insignificant, as was the change, $\Delta F(1,44)=1.19, p<.5, \Delta R^{2}=.02$. Finally, visual forward memory was added to the model, which remained insignificant, $F(7,43)=1.59, p<.5, R^{2}=.21$.

The second set of regressions considered number of omissions in the final position as the dependent variable. No outliers were found $(n=53)$. As above, the model considering only demographic variables was not significant. However, the addition of German receptive language ameliorated the model significantly, $\Delta F(1,47)=10.43$, $p<.01, \Delta R^{2}=.17$. Children with high German receptive language skills were more likely to have fewer final omissions, $b=-.14, p<.01$. Neither the addition of visuo-verbal n-back nor of visual forward memory significantly improved the model, though the addition of $n$-back memory explained a further $4 \%$ of variance.

The last stepwise regression of German omissions used omissions in the medial position as the dependent variable. One outlier was excluded $(n=52)$. German receptive language and omissions in the medial position were somewhat correlated, $r(50)=-.64, p<.05$, though not enough to risk suppression through additivity. The first step included only demographic variables, $F(4,47)=3.35, p<.05, R^{2}=.22$. AoO was a good individual predictor, $b=.27, p<.01$. The addition of German receptive language significantly improved the model, $\Delta F(1,46)=21.26, p<.001, \Delta R^{2}=.25$ and mitigated the role of AoO. German receptive language itself was significantly negatively associated with number of medial omissions, $b=-.76, p<.001$. The third 
step introduced the visuo-verbal n-back memory score, which-unlike when considering initial and final omissions-caused a noticeable improvement of the model, $\Delta F(1,45)=5.32, p<.05, \Delta R^{2}=.05$. Though German receptive language remained a significant individual predictor, $b=-.71, p<.001$, n-back memory was also negatively associated with number of medial omissions, $b=-1.62, p<.05$. Adding forward memory improved the model very slightly and non-significantly, $\Delta F$ $(1,44)=1.41, p>.5, \Delta R^{2}=.02$ (Figure 4 ).

As predicted, this finding supports primacy and recency effects indirectly. Since children who perform well in memory tasks - significantly in those with a verbal component - are less likely to make medial omissions than children whose memory scores are not as high, we extrapolate that the medial position is most vulnerable to poor memory abilities.

\section{Research question 3}

Research question three inquired into the relationship between positions of omissions in the Russian SRT to visuo-verbal and non-verbal visual memory, when demographic variables (age, sex, IQ) and Russian receptive language are taken into account. The same threefold stepwise regressions were performed as for the German SRT. Linearity, normality, multicollinearity, homogeneity and homoscedasticity were met for all data sets after any outliers were removed.

Beginning with errors of omission in the initial position, one outlier was removed, $(\mathrm{n}=52)$. Unlike for German, the model including only demographic variables was predictive, $F(3,48)=2.75, p<.05, R^{2}=.15$, with boys more likely to have more omissions, $b=-1.05, p<.05$. The addition of Russian receptive language mitigated the role of sex, but explained only a further $2 \%$ of variance and did not create a significantly better model. Adding n-back and forward memory did not significantly improve the model either.

The next set of stepwise regressions considered omissions in the final position as the dependent variable. Four outliers were removed $(n=49)$. The model using only demographic variables reached low significance, $F(3,45)=4.67, p>.01, R^{2}=.24$. Boys were significantly more likely to have a higher number of omissions in the final position than girls, $b=-2.11, p<.01$. The addition of Russian receptive language to the model significantly improved it, $\Delta F(1,44)=10.07, p<.01, \Delta R^{2}=.14$. Along with being individually negatively associated with omissions in the final position in its own right, $b=-.24, p<.01$, the Russian receptive language score reduced the importance of sex, $b=-1.38, p<.05$. In the third step, n-back memory was added. This further improved the model, $\Delta F(1,43)=7.14, p<.05$ and explained another $9 \%$ of variance. Russian receptive language remained highly significant, but n-back memory was also negatively associated, $b=-.41, p<.05$. Its addition negated the role of sex. Finally, adding visual forward memory further improved the model somewhat, though non-significantly, $\Delta F(1,42)=3.80, p>.1, \Delta R^{2}=.04$ (Figure 5). Visual memory was non-significantly positively associated with omissions in the final position, $b=.17, p<.1$, but its addition strengthened the individual predictive value of visuo-verbal $\mathrm{n}$-back memory significantly, $b=-.43, p<.01$.

In the third regression, the dependent variable was "omissions in the medial position." No outliers were found $(n=53)$. Analogous to the omissions in the initial position, the model including demographic variables significantly predicted number of omissions in the medial position with girls less likely to omit words in this 


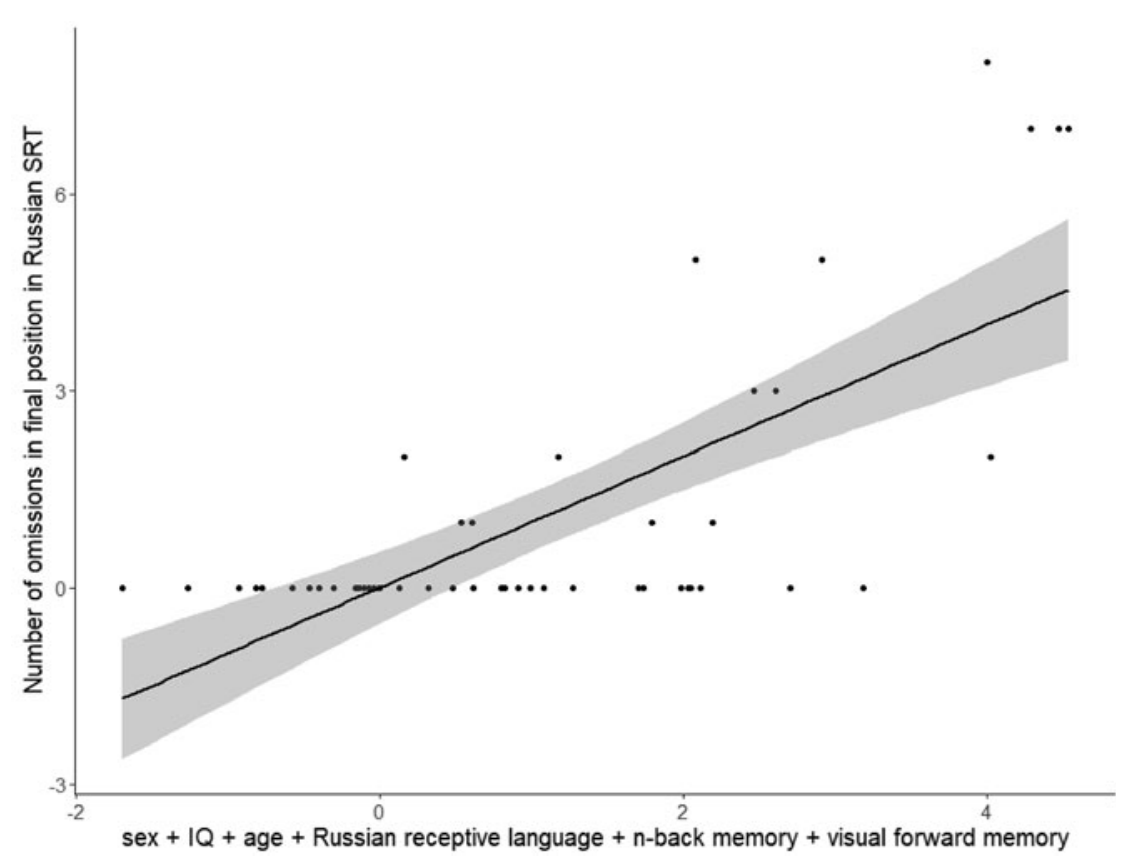

Figure 5. Scatterplot of regression of sex, IQ, age, Russian receptive language, n-back memory and visual forward memory with number of omissions in the final position in the Russian SRT

position, $b=-2.76, p<.01$. Again, this effect was totally mitigated by adding Russian receptive language, which is significantly associated with number of omissions in the medial position, $b=-.38, p<.001$, and improved the model significantly, $\Delta F(1,48)=$ $17.63, p<.001, \Delta R^{2}=.22$. The addition of memory scores did not improve the model, and explained no further variance. This finding does not align with predictions (iii) or (iv) for Russian. In the Russian SRT, the only position vulnerable to memory deficits is the final position; children with higher skills in visuo-verbal n-back memory, but with LOWER skills in visual forward memory are less likely to omit items here. This does not match the results from research question 1b: there seem to be recency effects in the Russian SRT. However, they are differentiated by memory rather than linguistic skills. The exact role of short-term and working memory skills is far less cut and dried than in the German SRT. Thus, prediction (iv) - that the effect of memory will be highly similar for both SRTs - cannot be confirmed.

\section{Discussion}

The current study assumed that language and memory are closely intertwined. To this effect, we analyzed the frequency and distribution of omission errors in a German and a Russian SRT performed by TD bilingual five-year-olds. We then related positions of omissions to a non-verbal visual short-term and a visuo-verbal n-back working memory test, while taking into account German and Russian receptive language, respectively. 
In this paper we have proposed a novel methodology for SRT analysis, considering an additional factor for processing costs in SRTs: namely, the position of an item in the sentence. Our first question was whether omission patterns show serial order effects. This was examined in two typologically different languages, specifically asking: are there certain positions in sentences which are especially vulnerable? If so, are they analogous to primacy and recency effects observed in recall tasks? If these effects from recall tasks pertain to SRTs, we may assume that there are lower processing costs involved in the beginning and end of a sentence, and that these positions will be less vulnerable than items within the sentence.

We found a significant negative correlation between number of omissions and identical repetition in both SRTs. This might seem trivial at first glance, but considering the strictness of the identical repetition criterion, it could not be taken for granted. Additionally, this shows that - though number and position of omissions are different across the two languages and, inevitably, a small number of children do have few omissions and a high number of other errors - the number of omissions, on the whole, is a reliable measure of how well children are able to reproduce a sentence in German and Russian.

We observed overall serial order effects in the SRTs in German and Russian: in contrast to Alloway and Gathercole (2005), we found that the medial position was especially vulnerable to omissions in both languages, showing a higher number than the final or initial position. This finding confirms a great body of literature from cognitive psychology on primacy and recency effects in other types of recall tasks (e.g., Yoo \& Kaushanskaya, 2016; Brown et al., 2017; Hitch et al., 2020), as well as some early studies on typical child language acquisition, such as Gleitman et al. (1984). Additionally, in German, those children whose identical repetition scores are better are more likely to maintain the initial and final positions and omit only in the medial position, while children with low identical repetition scores are more likely to omit items in all three positions. There was no association between identical repetition and omissions in specific positions vs. other positions in Russian, though this finding of non-significance might be due to the far smaller number of omissions in the Russian SRT. Position within the sentence is obviously an important factor alongside receptive language, which should be considered when evaluating sentence repetition.

The second and third research questions concerned the relationship between the positions of omissions and visual short-term and visuo-verbal working memory skills in German and Russian respectively. For each language, three stepwise hierarchical regressions were calculated. These reinforced the importance of serial order effects. In German and Russian, when demographic variables are controlled for, receptive language is significantly negatively associated with omissions in the medial and final positions, with the former being more strongly associated in German. The small effect of sex on omissions in the Russian SRT is presumably the product of socio-cultural influences in Russian families, supported by the fact that adding Russian receptive language eliminated this effect (for more on the relationship between gender and Russian-German bilingual language acquisition, cf. Gagarina \& Klassert, 2018, pp. 8-10). Omissions in the initial position cannot be predicted by receptive language skills in either language. This speaks to a relevant memory component, matching the findings by Allen et al. (2018) of primacy effects in sentence recall. 
The prominence of the final position, however, seems to go against Berry et al. (2018) who found that various verbal and visuo-spatial working memory measures predicted visual working memory in the first two of three serial positions, but not the third and final position. It is of note that adding the visual memory score strengthened the predictive value of n-back working memory on the final position in Russian. This implies that the n-back test does tap into both verbal and visual memory, but seems to show that the visual component is separate and not interrelated with number of omissions in the final position, in agreement with Berry et al. (2018). Further studies with larger Russian-speaking populations are necessary for conclusions on the full nature of this relationship.

The role of n-back working memory supports prediction (iii) on primacy and recency effects in German only. Visuo-verbal n-back working memory scores cannot predict the number of omissions in the initial position in either German or Russian. There is a robust primacy effect across languages, corroborating much of the literature (e.g., Allen et al., 2018; Alloway \& Gathercole, 2005 vs. Mainela-Arnold \& Evans, 2005, and apparently contradicting Bloom, 1990). In German, omissions in the final position cannot be predicted by memory skills either. This is partly in accordance with findings by Berry et al. (2018). The authors come to the conclusion that recency effects in visual working memory are "automatic and do[...] not draw on executive attention" (ibid., p. 248). Our findings for the German SRT support this hypothesis for verbal n-back working memory as well. In addition, the lack of interaction with omissions in the initial position implies that primacy effects in sentence recall might also be automatic, as defined by Berry et al. (2018).

In the final position in the Russian SRT, though, visuo-verbal n-back working memory is significantly associated with the number of omissions, and explains $9 \%$ of variance. This implies that the recency effects in the Russian SRT are not automatic, as argued for German. The final position, rather, is the most related to memory abilities, replicating Alloway and Gathercole's (2005) findings.

It is of note that there is a difference in which position can be predicted by working memory scores in each language, going against our basic prediction (iv) that the effects would be the same. In our study, there is a significant difference in receptive language scores (see Table 1), and number of omissions in the SRT (Figure 3), with children performing better in Russian. One possible explanation for the difference, then, is that children are more proficient in Russian, and thus rely more heavily on entrenched linguistic skills-activating long-term semantic memory-rather than non-language-specific working memory (i.e., the type of verbal memory activated in list recall) in the Russian SRT. This idea is supported by the findings on receptive language (itself entrenched in long-term memory), which interacts with omissions in the medial and final positions in both languages, but not with omissions in the initial position, a prominent position irrespective of language. This interaction implies complementarity between n-back memory and receptive language skills, with one compensating for the other if necessary. It is possible that the children are so successful at retaining the basic meaning of the sentence in Russian (reflected by relatively high receptive language skills, see Table 1), that the effects of recency and primacy are mitigated. If a child has then stored the first parts of the sentence, the highest processing load will be on the final position, which must be related to the rest of the sentence. This might explain the negative association between n-back working memory skills and omissions in the final position, i.e., the final position is most dependent on working memory. In German, the reverse would be true: the 
participants might be so inept at recalling content (reflected by relatively low receptive language skills) and rely so heavily on non-language-specific memory of words or phonological fragments (influenced heavily by the basic concepts of primacy and recency effects) that only those children with especially high working memory abilities are able to retain the medial position, while recency effects allow most children, even those with low working memory abilities, to fill the final slot in the sentences. This argument would imply that beyond general serial order effects, the children are using different, language-specific solutions in the two tests.

This interpretation of language-specific solutions to the SRT leads us to a second explanation for the difference in which position is associated with n-back working memory: typological variance. The Russian sentences contain fewer words and especially fewer function words, as matches typical sentence length. This surely contributes to the lower number of omissions found in the Russian SRT (see Supplementary Materials online).

Additionally, in German, linguistic knowledge in terms of expectations of language-specific structures, such as a closing bracket, might come into play. The German sentence bracket might offer structural linguistic support in recalling the final position, in our case specifically in the eleven sentences containing a sentence bracket ${ }^{4}$. Strengthened through recency effects, this seems to be the most plausible explanation for the lack of interaction between n-back working memory skills and omissions in the final position in German. The question of typological differences in the position of omissions in SRT repetitions can only be briefly speculated upon here, and must be tackled in future research, ideally using material designed specifically for this purpose.

The German SRT in this study was designed for better understanding of children's language skills in an L2, and both SRTs were intended for use in diagnostics of DLD within a larger test battery. There were no ceiling effects at age five in either test, though it was used here in a TD population. This may be due to the fact that bilingual children in the presence of reduced input and variability of acquisition path and timing show high diversity (cf. Peukert \& Gogolin, 2017). These SRT results clearly differentiate performance in TD bilingual children by including various levels of complexity in the SRT. However, the difference in complexity poses a challenge for the examination of positions of errors of omission. For the investigation of the position of errors alone, the complexity of sentences should be kept constant, while for a diagnostic tool the complexity of the sentences must increase. Our solution to this clash of interests was to apply the very broad position criterion described above. In future studies, other material must be piloted and used for more in-depth analysis. Additionally, future research should consider this type of analysis in monolingual children, to more fully understand any differences between monolingual and bilingual sentence processing and repetition.

Thus, our findings provide a novel perspective on the interpretation of the reasons for the identical or non-identical repetition of sentences. The finding of primacy and recency effects in an SRT challenges the interpretation of SRT data, especially omissions. Our findings indicate a working memory effect: the better a child's working memory capacity, the fewer omissions they are likely to produce in the

\footnotetext{
${ }^{4}$ These sentences are bracketed by particle verbs (sentences $1,5,6,15 \& 16$ ), modal verb constructions (sentences 8, $9 \& 21$ ) and past participle with auxiliary verbs (sentences 11, 13 \& 14; see Appendix, Table A1 for complete sentences).
} 
medial position in German and final position in Russian, irrespective of their language performance. This study provides support that working memory measured with a visuo-verbal n-back task explains to a certain extent the position of omissions in sentence repetition in both German and Russian. In an n-back memory task the subjects must maintain and manipulate information, i.e., they update information continuously. Updating is also required in the cognitive task of sentence repetition. Our results indicate that this ability helps maintain the most memory-dependent positions in each language, medial for German and final for Russian.

To conclude, the study aims to extend the general understanding of the relationship of SRTs and linguistic knowledge as well as non-verbal short-term and visuo-verbal working memory. The medial position had the highest percentage of errors in both languages. Receptive language was significantly associated with the number of errors in the medial and final positions in both languages, but not the initial position. In all models, including receptive language mitigated the effects of demographic variables (e.g., AoO, sex), re-affirming the status of the children as TD. The number of errors of omission in the medial position in German and final position in Russian was significantly associated with visuo-verbal n-back working memory. Our findings provide evidence for a crucial role of working memory interacting with linguistic skills in sentence repetition in both languages in Russian-German bilingual children.

Acknowledgements. Data was collected in the research project funded by the German Research Foundation Verbal and Non-Verbal Indicators for Identifying Specific Language Impairment in Successive Bilingual Preschoolers (DFG Az. LI 410/5-1 \& Az. GA 1424/3-1). We thank the German Research Foundation as well as all those who participated in the project for data collection, transcription and error coding.

Supplementary Material. For supplementary material accompanying this paper, visit https://oi.org/10. 1017/S0305000921000325

\section{References}

Abed Ibrahim, L., \& Fekete, I. (2019). What Machine Learning Can Tell Us About the Role of Language Dominance in the Diagnostic Accuracy of German LITMUS Non-word and Sentence Repetition Tasks. Frontiers in Psychology, 9. Retrieved from https://www.frontiersin.org/articles/10.3389/fpsyg.2018.02757/ full

Abed Ibrahim, L., \& Hamann, C. (2017). Bilingual Arabic-German and Turkish-German with and without specific language impairment: comparing performance in sentence repetition and nonword repetition tasks. In M. LaMendola, \& J. Scott (Eds.), Proceedings of the 41st annual Boston University conference on language development (pp. 1-17). Somerville, MA: Cascadilla Press.

Acheson, D. J., \& MacDonald, M. C. (2009). Verbal working memory and language production: common approaches to the serial ordering of verbal information. Psychological Bulletin, 135(1), 50-68.

Allen, R. J., Hitch, G. J., \& Baddeley, A. D. (2018). Exploring the sentence advantage in working memory: insights from serial recall and recognition. Quarterly Journal of Experimental Psychology, 71(12), 25712585.

Alloway, T. P., \& Gathercole, S. E. (2005). Working memory and short-term sentence recall in young children. European Journal of Cognitive Psychology, 17(2), 207-220.

Armon-Lotem, S., \& Meir, N. (2016). Diagnostic accuracy of repetition tasks for the identification of Specific Language Impairment (SLI) in bilingual children: evidence from Russian and Hebrew. International Journal of Language \& Communication Disorders, 51(6), 715-731.

Augst, G. (ed.). (1985). Der aktive Kinderwortschatz (kurz vor der Einschulung) nach Sachgebieten geordnet mit einem alphabetischen Register. Bern, Switzerland: Peter Lang.

Baddeley, A. D. (2012). Working memory: Theories, Models, and Controversies. Annual Review of Psychology, 63, 1-29. 
Berry, E. D. J., Waterman, A. H., Baddeley, A. D., Hitch, G. J., \& Allen, R. J. (2018). The Limits of Visual Working Memory in Children. Exploring Prioritization and Recency Effects with Sequential Presentation. Developmental Psychology, 54(2), 240-253.

Bishop, D. V. (1982). Test for reception of grammar. Oxford, UK: Medical Research Council.

Bishop, D. V. (2004). Specific Language Impairment: Diagnostic Dilemmas. In L. Verhoeven, \& H. van Balkom (Eds.), Classification of developmental language disorders: theoretical issues and clinical implications (pp. 309-326). Mahwah, NJ: Lawrence Erlbaum Associates.

Bloom, P. (1990). Subjectless sentences in child language. Linguistic Inquiry, 21(4), 491-504.

Bockmann, A.-K., \& Kiese-Himmel, C. (2012). ELAN-R. Elternfragebogen zur Wortschatzentwicklung im frühen Kindesalter. Göttingen, Germany: Beltz Test Gesellschaft Hogrefe.

Brown, L. A., Niven, E. H., Logie, R. H., Rhodes, S., \& Allen, R. J. (2017). Visual feature binding in younger and older adults. Encoding and suffix interference effects. Memory, 25(2), 261-271.

Conti-Ramsden, G., Botting, N., \& Faragher, B. (2001). Psycholinguistic markers for specific language impairment (SLI). Journal of Child Psychology and Psychiatry and Allied Disciplines, 42(6), 741-748.

Cowan, N., Wood, N. L., Wood, P. K., Keller, T. A., Nugent, L. D., \& Keller, C. V. (1998). Two separate verbal processing rates contributing to short-term memory span. Journal of Experimental Psychology: General, 127(2), 141-160.

Devescovi, A., \& Caselli, M. C. (2007). Sentence repetition as a measure of early grammatical development in Italian. International Journal of Language and Communication Disorders, 42(2), 187-208.

Ebbinghaus, H. (2013). Memory: a contribution to experimental psychology. Annals of Neurosciences, 20 (4), 155-156.

Fox, A. (2011). Test zur Überprüfung des Grammatikverständnisses: TROG-D (5th ed). Idstein, Germany: Schulz-Kirchner Verlag.

Gagarina, N., Klassert, A., \& Topaj, N. (2010). Sprachstandstest Russisch für mehrsprachige Kinder. ZAS Papers in Linguistics, 54, Special Issue.

Gagarina, N., Klassert, А., \& Topaj, N. (2015). Тест по русскому языку для билингвальных детей. [Russian language proficiency test for multilingual children]. St. Petersburg: Zlatoust.

Gagarina, N., \& Klassert, A. (2018). Input Dominance and Development of Home Language in RussianGerman Bilinguals. Frontiers in Communication, 3. Retrieved from https:/www.frontiersin.org/articles/ 10.3389/fcomm.2018.00040/full

Gagarina, N., \& Valentik-Klein, E. (2013). NWR for preschool bilingual children with heritage Russian. Unpublished Manuscript, Leibniz-Zentrum Allgemeine Sprachwissenschaft, Berlin, Germany.

Gillam, R. B., Cowan, N., \& Marler, J. A. (1998). Information processing by school-age children with specific language impairment: evidence from a modality effect paradigm. Journal of Speech, Language and Hearing Research, 41(4), 913-927.

Gleitman, L. R., Newport, E. L., \& Gleitman, H. (1984). The current status of the motherese hypothesis. Journal of Child Language, 11(1), 43-79.

Grimm, H., Aktas, M., \& Frevert, S. (2010). SETK 3-5. Sprachentwicklungstest für drei- bis fünfjährige Kinder. Diagnose von Sprachverarbeitungsfähigkeiten und auditiven Gedächtnisleistungen (2nd ed.). Göttingen, Germany: Hogrefe.

Grimm, H., \& Doil, H. (2006). ELFRA. Elternfragebögen für die Früherkennung von Risikokindern (2nd ed.). Göttingen, Germany: Hogrefe.

Hamann, C. (2013). Sentence Repetition in German. Poster presented at the 8th MC \& WGs Meeting, Lisbon, Portugal.

Hamann, C., \& Abed Ibrahim, L. (2017). Methods for identifying Specific Language Impairment in bilingual populations in Germany. Frontiers in Communication, 2(19). Retrieved from https://www. frontiersin.org/articles/10.3389/fcomm.2017.00016/full

Hamann, C., Chilla, S., Gagarina, N., \& Abed Ibrahim, L. (2017). Syntactic complexity and bilingualism:. In E. Di Domenico (Ed.), Syntactic complexity from a language acquisition perspective (pp. 142-177). Newcastle upon Tyne, UK: Cambridge Scholars Publishing.

Held, J., Lindner, K., \& Gagarina, N. (2013). n-back-Aufgaben mit Geräuschen. Ein Test für Vorschulkinder. Unpublished Manuscript, University of Munich, Munich, Germany.

Hitch, G. J., Allen, R. J., \& Baddeley, A. D. (2020). Attention and binding in visual working memory. Two forms of attention and two kinds of buffer storage. Attention, Perception \& Psychophysics, 82, $280-293$. 
Kauschke, C., \& Siegmüller, J. (2009). Patholinguistische Diagnostik bei Sprachentwicklungsstörungen. Munich, Germany: Elsevier.

King, T. H. (1995). Configuring topic and focus in Russian. Dissertations in Linguistics. Palo Alto, CA: Stanford University Press.

Klem, M., Melby-Lervåg, M., Hagtvet, B., Halaas Lyster, S.-A., Gustafsson, J.-E., \& Hulme, C. (2015). Sentence repetition is a measure of children's language skills. Developmental Science, 18(1), 146-154.

Lindner, K., Held, J., Lomako, J., \& Gagarina, N. (2014). Verbale und nonverbale Indikatoren zur Identifizierung von umschriebenen Sprachentwicklungsstörungen bei sukzessiv bilingualen Kindergartenkindern. Forschung Sprache 2, 58-68. Retrieved from https://www.forschung-sprache.eu/ fileadmin/user_upload/Dateien/Heftausgaben/2014-2/FS_2014-02_58_68_Lindner_Held_Lomako_ Gagarina.pdf

Lindner, K., Schmitt, D., \& Kühfuss, L. (2013). Satzwiederholung im Deutschen. Ein Test für Vorschulkinder. Unpublished Manuscript, University of Munich, Munich, Germany.

MacWhinney, B. (2000). The CHILDES project: tools for analyzing talk. Mahwah, NJ: Lawrence Erlbaum Associates.

Mainela-Arnold, E., \& Evans, J. (2005). Beyond capacity limitations: determinants of word recall performance on verbal working memory span tasks in children with SLI. Journal of Speech, Language and Hearing Research, 48(4), 897-909.

Mainela-Arnold, E., Misra, M., Miller, C. A., Poll, G. H., \& Park, J. S. (2012). Investigating sentence processing and language segmentation in explaining children's performance on a sentence-span task. International Journal of Language and Communication Disorders, 47(2), 166-175.

Marinis, T., \& Armon-Lotem, S. (2015). Sentence repetition. In S. Armon-Lotem, J. de Jong, \& N. Meir (Eds.), Methods for assessing multilingual children: disentangling bilingualism from language impairment (pp. 95-124). Clevedon, UK: Multilingual Matters.

Marinis, T., Chiat, S., Armon-Lotem, S., Piper, J., \& Roy, P. (2011). School-age sentence imitation test-English 32 (SASITE32). Unpublished test, City University, London, UK. Retrieved from www.city. ac.uk/_data/assets/word_doc/0010/118864/SASIT-E32-Protocol,-Structures-and-Scoresheet.doc

Meir, N. (2018). Morpho-syntactic abilities of unbalanced bilingual children: a closer look at the weaker language. Frontiers in Psychology, 13. Retrieved from https://www.frontiersin.org/articles/10.3389/ fpsyg.2018.01318/full

Meir, N., \& Armon-Lotem, S. (2015). Disentangling bilingualism from SLI in heritage Russian: the impact of L2 properties and length of exposure to the L2. In C. Hamann, \& E. Ruigendijk (Eds.), Language acquisition and development: proceedings of GALA 2018 (pp. 299-314). Newcastle upon Tyne, UK: Cambridge Scholars Publishing.

Meir, N., Walters, J., \& Armon-Lotem, S. (2016). Disentangling SLI and bilingualism using sentence repetition tasks: the impact of L1 and L2 properties. International Journal of Bilingualism, 20(4), $421-452$.

Meringer, R., \& Mayer, C. (1895). Versprechen und Verlesen: eine psychologisch-linguistische Studie. Stuttgart, Germany: Göschen.

Moll, K., Hulme, C., Nag, S., \& Snowling, M. J. (2015). Sentence repetition as a marker of language skills in children with dyslexia. Applied Psycholinguistics, 36(2), 203-221.

Nag, S., Snowling, M. J., \& Miroković, J. (2018). The role of language production mechanisms in children's sentence repetition: evidence from an inflectionally rich language. Applied Psycholinguistics, 39(2), 303-325.

Peukert, H., \& Gogolin, I. (Eds.) (2017). Dynamics of Linguistic Diversity. John Benjamins.

Polišsenská, K., Chiat, S., \& Roy, P. (2015). Sentence repetition: what does the task measure? International Journal of Language and Communication Disorders, 50(1), 106-118.

Poll, G. H., Miller, C. A., Mainela-Arnold, E., Adams, K. D., Misra, M., \& Park, J. S. (2013). Effects of children's working memory capacity and processing speed on their sentence imitation performance. International Journal of Language and Communication Disorders, 48(3), 329-342.

Potter, M. C., \& Lombardi, L. (1990). Regeneration in the short-term recall of sentences. Journal of Memory and Language, 29(6), 633-654.

R Core Team. (2018, December 20). $R$. A language and environment for staistical computing. $R$ version 3.5.2. Retrieved from www.R-project.org/ 
Riches, N. G. (2012). Sentence repetition in children with specific language impairment: an investigation of underlying mechanisms. International Journal of Language and Communication Disorders, 47(5), 499-510.

Roid, G., Miller, L., Pomplun, M., \& Koch, C. (2013). Leiter-3: international performance scale (3 ${ }^{\text {rd }}$ ed.). Wood Dale, IL: Stoelting Company.

Švedova, N. J. (1982). Grammatika russkogo literaturnogo jazyka: sintaksis. Moscow: Prosvescenie.

Tabachnick, B. G., \& Fidell, L. S. (2007). Using multivariate statistics (5th ed.). Allyn \& Bacon/Pearson Education.

Thordardottir, E., \& Brandeker, M. (2013). The effects of bilingual exposure versus language impairment on nonword repetition and sentence imitation scores. Journal of Communication Disorders, 46(1), 1-16.

Tuller, L., Hamann, C., Chilla, S., Ferré, S., Morin, E., Prevost, P., dos Santos, C., Abed Ibrahim, L., \& Zebib, R. (2018). Identifying language impairment in bilingual children in France and Germany. International Journal of Language \& Communication Disorders, 53(4), 888-904.

von Buuren, S., \& Groothuis-Oudshoorn, K. (2011). mice: Multivariate imputation by chained equations in R. Journal of Statistical Software, 45(3), 1-67. Retrieved from https://www.jstatsoft.org/article/view/ v045i03

Wagner, J., Held, J., \& Lindner, K. (2013). Nachsprechaufgaben mit nonwords im Deutschen. Ein Test für Vorschulkinder. Unpublished Manuscript, University of Munich, Munich, Germany.

Wettstein, P. (1987). Logopädischer Sprachverständnis-Test LSVT. Zurich, Switzerland: Heilpädagogisches Seminar Abteilung Logopädie.

Yoo, J., \& Kaushanskaya, M. (2016). Serial-Position Effects on a Free-Recall Task in Bilinguals. Memory, 24(3), 409-422.

Zokaei, N., Heider, M., \& Husain, M. (2014). Attention is required for maintenance of feature binding in visual working memory. The Quarterly Journal of Experimental Psychology, 67(6), 1191-1213.

Cite this article: Stadtmiller E, Lindner K, Süss A, Gagarina N (2022). Russian-German five-year-olds: What omissions in sentence repetition tell us about linguistic knowledge, memory skills and their interrelation. Journal of Child Language 49, 869-896. https://doi.org/10.1017/S0305000921000325 